American Journal of Environmental Sciences 6 (1): 1-10, 2010

ISSN 1553-345X

(C) 2010 Science Publications

\title{
Green Methodologies to Test Hydrocarbon Reservoirs
}

\author{
Francesca Verga and Vera Rocca \\ DITAG Department, Politecnico di Torino, Corso Duca degli Abruzzi 24, 10129 Torino, Italy
}

\begin{abstract}
Problem statement: The definition and the economic viability of the best development strategy of a hydrocarbon reservoir mainly depend on the quantity and type of fluids and on the well productivity. Well testing, consisting in producing hydrocarbon to the surface while measuring the pressure variations induced in the reservoir, has been used for decades to determine the fluid nature and well potential. In exploration and appraisal scenarios the hydrocarbons produced during a test are flared, contributing to the emissions of greenhouse gases. Approach: Due to more stringent environmental regulations and a general need for reduced operating expenses, the current industry drivers in today's formation evaluation methodologies demand short, safe, cost-effective and environmentally friendly test procedures, especially when conventional tests are prohibitively expensive, logistically not feasible or no surface emissions are allowed. Different methods have been proposed or resuscitated in the last years, such as wireline formation tests, closed chamber tests, production/reinjection tests and injection tests, as viable alternatives to conventional well testing. Results: While various short-term tests, test procedures and interpretation methods are apparently available for conducting successful tests without hydrocarbon production at the surface, clarity is lacking for specific applications of these techniques. An attempt to clarify advantages and limitations of each methodology, particularly with respect to the main testing target is pursued in this study. Specific insight is provided on injection testing, which is one of the most promising methodology to replace traditional well testing in reservoir characterization, except for the possibility to sample the formation fluids. Conclusion/Recommendations: Not a single one method but a combination of more methodologies, in particular injection testing and wireline formation testing, is the most promising strategy to achieve all the targets of a conventional well testing with no surface hydrocarbon production, increased safety during operations and reduction of the testing costs
\end{abstract}

Key words: Unconventional well testing, injection testing, wireline formation testing, surface emissions

\section{INTRODUCTION}

The definition and the economic viability of the best development strategy of a hydrocarbon reservoir mainly depend on the quantity and type of fluids, on the productivity of the wells which need to be drilled to bring the fluids to the surface and on the reservoir location. Well tests have been widely used for several decades in the oil industry for estimation of reservoir characteristics such as initial pressure, fluid type, effective permeability and identification of reservoir barriers or boundaries in the formation volume investigated by the test (Coelho et al., 2005). Information collected during well testing usually consists of flow rates, pressure and temperature data, in addition to fluid samples (Woie et al., 2000). In conventional well testing a pressure disturbance is induced in the reservoir by producing the well at subsequent constant fluid rates. Flow rate changes give rise to a sequence of pressure drawdown and buildup periods. The response of the reservoir in terms of pressure at the well is then associated to the imposed production rates and matched with proper analytical or simplified numerical models in order to estimate the sought reservoir properties. According to their duration most of the tests are performed under transient conditions (no boundary of the reservoir are reached by the pressure sink) or under the so called late transient conditions (some but not all of the boundaries are detected). Therefore, the methodology adopted for well test interpretation is generally called pressure transient analysis.

There is no single method of testing and sampling that is fit for purpose under every circumstance. The

Corresponding Author: Francesca Verga, DITAG Department, Politecnico di Torino, Corso Duca degli Abruzzi 24, 10129 Torino, Italy 
selection of the test type, sequence and duration must be balanced against operational risk, environmental constraints and value derived from affecting early decisions on project appraisal or development. However, conventional well testing methods usually involve surface production of fluid or changing rate at the surface.

In exploration and often in appraisal scenarios, surface facilities to store the reservoir fluids are not available and hence the fluid is discharged or flared. Burning hydrocarbons during cleanup and well testing operations produces significant amounts of emissions that contain unburned hydrocarbons, carbon monoxide and nitrogen oxides, which in turn produce acid rain, smog, ozone at ground levels and greenhouse gases in the upper atmosphere. Acid rain depletes soil, pollutes water, damages forests, endangers animal habitats and food chains and corrodes human-made structures, such as buildings, statues, automobiles and other artifacts made of stone or metal. Smog and ozone cause human respiratory ailments, such as asthma, bronchitis and emphysema. Most scientists believe that greenhouse gases are a major cause of global warming. Increased concentrations of water vapor, carbon dioxide, methane and other greenhouse gases trap heat energy in the earth's atmosphere. A gradual rise in the earth's surface temperature is expected to melt polar ice caps and glaciers, expanding ocean volume and raising sea level, flooding some coastal regions and even entire islands (El-Khazindar et al., 2002). For this reason atmospheric emissions feature at the top of the list of the environmental regulations so far and it is a matter of fact that in the recent years politics about HSE became more strict and relevant. In particular the European Union negotiated the Kyoto Protocol for its members: all directives that it inspired have the potential to apply to offshore industry (Garland, 2002; 2005).

The evolution in HSE's policies have changed the viewpoint with which conventional well tests are evaluated. Furthermore, not only do atmospheric emissions have a damaging impact on the environment, but they also impose an economic impact: the cost of the oil and gas flared and the cost of the equipment used during the flaring operations as performing a well test typically costs several million dollars mostly due to required rig time and loss of production. Because of the high costs involved in well test operations, especially in offshore exploration wells, the test type must be carefully chosen and properly designed in order to meet its required objectives at the lowest cost (Hollaender et al., 2002).

\section{MATERIALS AND METHODS}

Guidelines in defining new methodologies for reservoir characterization: Due to more stringent environmental regulations and a general need for reduced operating expenses, the current industry drivers in today's formation evaluation methodologies demand short, cost-effective and environmentally friendly test procedures, especially in exploration wells. This is particularly true in deepwater and arctic environments where conventional tests can be prohibitively expensive or logistically not feasible (Soliman et al., 2004; 2005) as well as in several protected areas of the world where no emissions are allowed to the surface. By attaining these needs, the advantages of improved Return On Investment (ROI), reduced operating expense, improved asset utilization, improved personnel safety and reduced risks to the environment will result. These environmental risks particularly target flaring practices.

The regulatory agencies have not been the only driving force in the attainment of more restrictive environmental regulations; the oil companies have also been drivers. Several companies have initiated review of the processes that require flaring. Before these processes can be employed, internal justifications must prove that the planned flaring operation to gain information about a well or field will outweigh the increased costs, safety liability and potential environmental damage associated with flaring a well. Other companies have decided to suspend flaring altogether, or to use their internal $\mathrm{CO}_{2}$ quota trading between projects to reduce emissions. On the government side, taxation or outright bans on flaring of liquids, gases or both in combination with other emission restrictions are the methods employed to reduce harmful flaring. Norway and Denmark charge $\mathrm{CO}_{2}$ taxes based on the amount of hydrocarbons burned. In other areas, countries have increased permit costs if flaring while testing takes place. In parts of the Caspian Sea, there is a ban on any discharge to sea, while the Middle East is heading in the same direction as California, banning all flaring if possible.

During the time frame in which the above direction has taken place, the oil companies and the industry in general has had to weather a substantial lowering of oil prices. This has intensified the industry's need for more efficient operation and cost cutting. This pressure has not eased although oil prices have now recovered. Improved ROI achieved by faster decision making, reducing OPEX and improving efficiency in asset use are some of the methods now being employed in the fight for operational strategies that can increase profit margins. This has been manifested by the interest 
Am. J. Environ. Sci., 6 (1): 1-10, 2010

operators have shown in any technology that promises to cut rig time, reduce financial risk in field development and shorten the time between data gathering and decision making.

The industry also has demonstrated the desire to improve personnel safety. Although the industry as a whole has already achieved a lost-time incident rate that is less than industry average for any given country, it continues to pursue improvements in this area.

The consequence of more stringent environmental regulations, safety concerns and economical considerations is that the oil industry is being forced away from traditional well testing and formation evaluation techniques. The alternative but less accurate reservoir evaluation methods have given certain shortterm benefits to the industry. The operational efficiency has improved because less time-consuming methods to evaluate the field prospects have been used. In addition, the personnel and environmental safety records have been improved due to the exposing of fewer personnel to uncertain well conditions and testing of the wells with processes that draw less fluid from the reservoirs. There are some immediate financial benefits gained since the cost of the alternative evaluation methods is normally less than a full-scale traditional well test and the technical requirements to the rigs are less. The speed of decision making has also improved since less data to evaluate is gathered and the equipment for these tests has been improved. However, reliance on testing methods that might not provide accuracy in data collection increases the financial risk to the industry and over time could result in less efficient resource utilization. The long-term downside is that the oil industry as a whole is exposing itself to higher and higher risks because the generated data often do not allow accurate assessment of the reservoir. The ultimate challenge to the industry, therefore, is to find an answer to the question of how industry drivers can be merged in a coherent and reliable approach to formation evaluation.

Objectives and types of unconventional well testing: In 1998, operator, government and service company representatives met for a workshop in Scotland to begin investigating methods to develop new formation evaluation tools. The overriding outcome of the meeting was the need for testing systems that could eliminate or considerably minimize flaring. As a result, a joint-industry project generated by major oil companies requested that service companies provide proposals on how they could develop an alternative testing system. During the initial design stage of the system, a comprehensive survey of industry requirements for such a system was undertaken. This resulted in the identification and definition of the following list of needs:
- Representative reservoir fluid samples, in two forms: Small sample collected under flowing reservoir conditions suitable for PVT analysis; large sample of 1-20 bbl (depending on customer preference) for refining studies

- Near wellbore reservoir parameters, which include: initial reservoir pressure; static and dynamic bottomhole temperature; permeability; permeability damage in the near wellbore (skin) due to drilling mud invasion occurring during well drilling and completion operation

- Productivity potential: Estimation of possible production rates from a well

Recently, the interest in non-conventional well tests has developed in the area of reservoir exploration and appraisal. In the vast majority of situations associated with exploration activities, there is no infrastructure and equipment in place to collect and export the hydrocarbons produced during well tests, thus it is a common practice to burn the produced fluids. As previously discussed, the demands to reduce emissions during well tests put enormous pressure to avoid these tests altogether. This brings large uncertainties to the reservoir appraisal and increases the investment risk if a decision is made to sanction a project or to develop the field. In most cases, drilling additional wells to reduce appraisal risks is not an option in view of the enormous costs of wells in frontier and deep-water explorations areas (Soliman et al., 2005; Levitan, 2003). As a general worldwide trend offshore well testing activities are slowly fading and large-scale extensive well testing projects are far and few in between. In Alberta and elsewhere in North America, the driving force towards inexpensive tests is the marginal economics of low deliverability wells. Either way, there is an increasing trend towards these green tests to replace conventional well tests (Levitan, 2002).

Alternative methods in well testing have been structured in the last years. Advances in gauge, tool assembly and telemetry technology have collectively paved the way for conducting short-term tests. Techniques developed for analysis of these tests rely on modern gauge capability for accuracy and quick measurement of pressure change with time as well as accurate compensation for the effect of temperature. However, while various short-term tests, test procedures and interpretation methods are available for conducting successful short-term tests, clarity is lacking for specific applications of these methods (Soliman et al., 2004; 2005).

A valid contribution to the review and discussion of technologies such as wireline formation tests, closed 
chamber tests, production/reinjection tests and injection tests as viable alternatives to conventional well testing can be found in the technical literature (Coelho et al., 2005; Woie et al., 2000; El-Khazindar et al., 2002; Hollaender et al., 2002; Banerjee et al., 1998; Beretta et al., 2006; 2007).

Well completion: The word "completion" itself means conclusion and more particularly in the case of the oil industry the conclusion of a borehole that has just been drilled. Completion is therefore the link between drilling the borehole as such and the production phase. As a result, completion involves all of the operations designed to make the well produce, in particular connecting the borehole and the pay zone (the zone consisting of reservoir rock which contains oil and/or gas that can be recovered), equipping the well, putting it on stream and assessing it. Completion is highly dependent on the phases that precede and follow it and is often even an integral part of them (Perrin et al., 1999).

There are many factors influencing completion. One of this is the purpose of drilling that can vary depending on the well, with a distinction basically made between exploration wells, appraisal wells and development wells. Another factor that can affect a good completion are the parameters related to the environment. There may be constraints on operations due to the country or site where the well is located, whether on land (plain or mountain, desert, agricultural or inhabited area) or offshore (floating platform, development from a fixed platform or by a subsea wellhead). The restrictions may involve the difficulties in obtaining supplies, the available spaces and utilities, the safety rules that have to be enforced and certain operations that may be or may not be possible. Meteorological and, if relevant, oceanographic conditions must be also taken into account.

The successful production of oil and gas depends on the proper performance of casing, which is cemented to the drilled formations and serves as a structural retainer in the well and tubing string or production conduit, which runs inside the casing and conducts oil or gas from subsurface strata to ground level (Bradley, 1987). The packer is one of the most important tools in the tubing string. It is a device which is positioned within a wellbore above the pay zone to seal the annulus between the interior of the well casing and the exterior of the tubing string, enabling efficient flow from or injection into the formation. Communication between the formation and the tubing is obtained by ripping the casing with perforating guns.
Closed chamber testing: A Closed Chamber Test (CCT) is conducted producing the reservoir fluids in the tubing string. The well is shut in at the surface when producing, so as to create a closed chamber of known volume into which the reservoir fluids can flow and open at the surface only when shut in at the formation. The chamber is formed by the space between the wellhead valve and the changing level of the fluid with which the string is filled prior to testing. The string can be filled with a liquid (typically, the drilling mud or completion fluid) as well as with nitrogen at a relatively low pressure (Alexander, 1976). A CCT begins with the instantaneous removal of a volume of fluid from the wellbore. The resulting decrease in bottom hole pressure causes an immediate influx of reservoir fluids. When the well begins to flow, the nitrogen or air is compressed and the volume of fluid inflow can be calculated as a function of time by monitoring the surface pressure in the string. Afterword, the bottomhole valve is closed to halt flow when the surface pressure reaches a value calculated prior to testing. This ensures that a known amount of production has taken place (Simmons and Grader, 1985).

Some authors report that the CCT technique is a valid alternative to conventional well testing because it has a lot of advantages such as: It offers great security and safety; the test provides formation permeability, reservoir pressure, skin and, depending on the volume flowed, a fluid sample; it provides a basis for rate determination, particularly for gas wells; it appears particularly suited to testing low permeability gas wells; it is a very simple methodology and it can be performed with existing equipment that requires limited extra hardware; a particular feature of CCT is that the test may be switched to a conventional test, i.e., the surface valve may be opened at any point during flow periods (Hollaender et al., 2002; Soliman et al., 2004; 2005). However, CCT's have a lot of disadvantages: There is no assurance about the quality of the sampling, as drilling and completion fluids might be produced rather than reservoir fluids; only one test is possible and once the wellbore is filled no other test can be done; the fact that there is only a limited volume to be produced during the test has a large impact on the radius of investigation of such a test; depths of investigation from CCT are generally in one hundred of feet which makes them inapplicable for boundary or barrier detection; complex wellbore dynamics affects pressure response; the well may not be 'clean' prior to the test and hence the results may be distorted.

In conclusion, even though CCT appears as a very attractive method to perform a green test, it has several 
shortcomings in terms of sampling quality, flexibility and information obtainable. For these reasons, it cannot be considered suitable to fully replace conventional well testing (Hollaender et al., 2002).

Wireline formation testing: An overlap exists between the objectives of Wireline Formation Testing (WFT) and conventional well testing and whether one can replace the other depends on the specific targets.

WFT consists in producing the reservoir fluids directly in the wellbore using a downhole pump so as to avoid hydrocarbon flow at the surface. After this short production period, a pressure build-up occurs. Pressure is monitored during the production and subsequent shut-in period. The result is a sort of mini test of the formation, hence the name mini-DST, for reservoir dynamic characterization. The objectives of a WFT are: Determine initial formation pressures at zones of interest and establish pressure gradients for fluid type identification; recognize zones in hydraulic communication or isolation; collect representative formation fluid samples; estimate formation fluid mobility. Additionally, estimates of spherical permeability, vertical to horizontal permeability ratio and formation skin factor can be obtained (Whittle et al., 2003). The great advantages of WFT are that, in most cases, the pressure test can be performed in a matter of minutes (WFT tools are highly interactive tools); representative reservoir fluid samples can be recovered; there is no surface production.

The major limitation of WFT is generally agreed to be the scale of measurement, both in terms of producing pay and radius of investigation. In many cases predicting the future performance of the well is limited by the upscaling process that needs to be applied and the uncertainty degree dramatically increases in the presence of rock heterogeneity (Beretta et al., 2006). As a consequence of the reduced depth of investigation, WFT are inappropriate for locating reservoir barriers, they cannot provide the information on gas deliverability, which is sometimes required for gas contracts, nor can they provide large volume samples.

Although it cannot totally replace a traditional production test, WFT has emerged as a legitimate alternative to it, as wireline testing increasingly fulfils the majority of formation evaluation objectives. Since the late 1990s, WFT has taken over more and more duties of the formation testing operations in many upstream exploration activities, particularly in expensive offshore projects and new frontiers. The North Sea and Canadian offshore are typical examples. As a result, compliance to environmental constraints and a significant reduction in the exploration costs have been achieved.

Production-reinjection testing: The Downhole Production/reinjection Test (DPT) method is a well test procedure that allows production from a selected layer (production layer) and injection of the produced volume into another adequate zone (injection zone) through a downhole pump, while flow rate, pressure and temperature data are monitored and controlled from surface. The injection zone can be located above or below the production zone, but having it above the tested layers offers several advantages, the most obvious of which is the fact that there is no need to drill the well to a greater depth. This methodology permits to test both production and injection layers and moreover fluid samples can be taken during the flow period (Woie et al., 2000; Hollaender et al., 2002).

The production/reinjection test method shows a lot of advantages that can be summarized as follows: It significantly reduces the onshore and offshore logistics operation and thus the economical aspects; because no hydrocarbons flow to surface during the test, the risk and safety issues of conducting a well test are significantly reduced; production and injection zone may be characterized simultaneously; temporary storing of the produced fluids in the wellbore is not required, as the fluids can be reinjected directly after being produced; high-risk operations in deep water are also minimized; DPT has a wide range of applications for reservoir heterogeneity determination (Woie et al., 2000; Hollaender et al., 2002).

Unfortunately, conflicting with the advantages, there are also a lot of disadvantages: A suitable injection zone is required, preferably above the targeted reservoir and the choice of it is crucial in many respects to the success of the test; the injected fluids may contain a significant proportion of fines in suspension that may plug the injection zone and considerably slow down the flow; potentially larger problems exist with unconsolidated formations; pressure data quality might be poor because of induced vibrations and also due to temperature changes; the impact of having communication between the injected and producing zones may mislead the interpretation; there is an increased risk of stuck pipe (Woie et al., 2000; Hollaender et al., 2002). Therefore, the methodology of production/reinjection test is challenging from several aspects, mostly related to the capability of finding an adequate injection zone across the wellbore, which would not affect the test data and have the ability to accommodate the produced fluids. The issue of 
hardware integrity in difficult conditions must also be taken into account (Hollaender et al., 2002).

The future of production/reinjection tests depends in a large part upon the development of an adapted tool providing good quality data, the ability to efficiently monitor the test, having pumps with enough power to maintain injectivity by fracturing the injection zone if necessary and adapted and reliable sampling tools.

Injection testing: One of the most interesting new unconventional well testing methodologies is injection testing. Injection tests eliminate emissions during reservoir appraisal and, except for fluid sampling, can provide all the information needed to estimate the well productivity at a reasonably low cost and with a good degree of reliability (Levitan, 2002; Beretta et al., 2007).

An injection test consists substantially in injecting a fluid, commonly a brine or diesel, in a potential oil pay zone and in monitoring the pressure response during the injection period and the subsequent so called fall-off period, in which the well is shut in and the pressure tends to return to the equilibrium value. Although an injection/fall-off test is similar to a conventional drawdown/build-up test, a distinction between the two is necessary when the properties of the injected and reservoir fluids are different (Gan et al., 2002). In fact, the analytical models adopted to interpret conventional or not conventional production tests have been developed under the hypothesis of mono-phase flow in the formation. As an example, in an undersaturated oil reservoir, the water is assumed to be at the irreducible saturation and therefore characterized by null permeability and the pressure response is a function of the effective permeability to oil which is the only flowing phase.

The physics of injection tests is characterized by the presence and movement of two phases in the reservoir, the hydrocarbons originally in place and the injected fluid. Fluid saturations change dynamically during injection in both space and time and the permeability of the reservoir rock to each fluid will be dependent on fluid saturation through the relative permeability curves. A dynamic interface will form in the reservoir between injected and reservoir fluids which can be assumed piston-like only if the mobility of the reservoir fluid is greater than that of the injected fluid. Mobility is the ratio between the effective permeability and the fluid viscosity. Moreover relative permeability will play an important role (Levitan, 2002). The injected fluid is usually at a lower temperature than the reservoir fluid, so injection also induces temperature changes in the near wellbore zone, which in turn affect the pressure behavior due to the temperature effects on the hydrocarbon and water viscosities.

Several analytical models were developed in time for production test analysis in order to depict and interpret the monophase fluid flow through a porous medium. Although these are the most widely used instruments for well test interpretation, they cannot quantitatively describe the flow of multiple phases in reservoirs as it occurs during injection tests.

If the injection fluid is immiscible with the reservoir fluid, the saturation distribution during injection can be described by the presence of three zones (Sosa et al., 1981), as shown in Fig. 1 (Verga et al., 2008):

- A water zone near the wellbore, where water has completely displaced the oil and the saturation reaches the constant value $1-S_{\mathrm{hr}}\left(\mathrm{S}_{\mathrm{hr}}\right.$ indicates the residual hydrocarbon saturation in the rock pores)

- A transition zone, where the water saturation progressively decreases from the maximum value, $1-S_{\mathrm{hr}}$, to the irreducible value, $S_{\mathrm{wi}}$

- An undisturbed zone, where the water saturation is equal to the irreducible value, $S_{\mathrm{wi}}$

During the pressure fall-off phase subsequent to the injection period, only little changes in saturation values are registered (Levitan, 2002). The injected fluid front can be considered stable at the time scale of the test (typically hours) because it only slightly moves due to capillary and gravitational forces in days or weeks.

A thorough discussion on the applicability of analytical interpretation models when different fluids are interacting in the reservoir can be found in the technical literature (Beretta et al., 2007; Gan et al., 2002; Abbaszadeh and Kamal, 1987; Bourdet, 2002). If the transition zone is neglected two zones with different mobilities and compressibilities are left.

If, additionally, the assumption is made that a sharp, vertical interface, as in piston-like displacement, separates the inner zone where the original fluid has been displaced from the outer undisturbed zone,

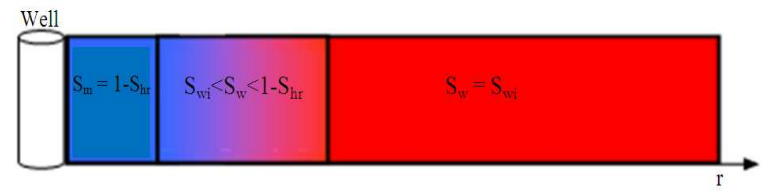

Fig. 1: Qualitative fluid distribution at the end of injection 
Am. J. Environ. Sci., 6 (1): 1-10, 2010

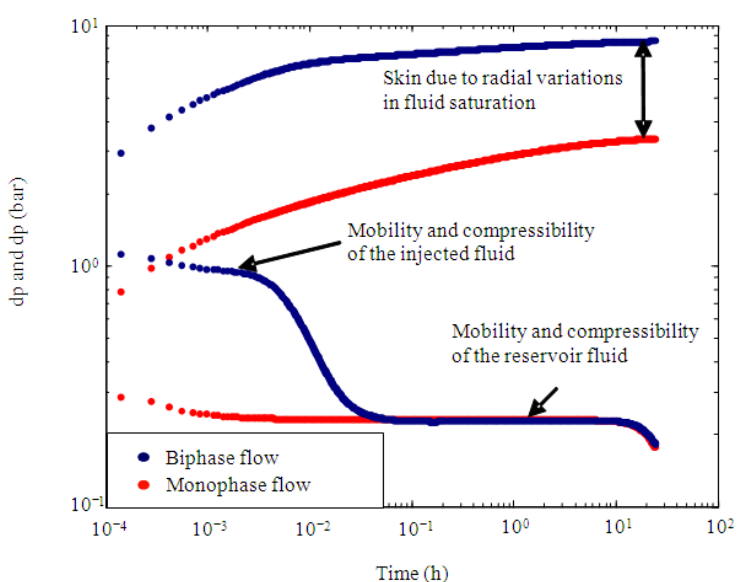

Fig. 2: Fall-off pressure derivatives

an analytical solution, namely the so called radial composite model, can be applied to describe the fluid distribution. As it can be observed in Fig. 2, two horizontal stabilizations are shown by the pressure derivative on the diagnostic plot corresponding, respectively, to radial flow in the near wellbore (inner) region, flushed by the injection fluid, and radial flow in the undisturbed hydrocarbon (outer) region. Each stabilization is a function of the mobility and compressibility of the region through which the pressure disturbance is propagating.

The total skin $\left(\mathrm{S}_{\mathrm{t}}\right)$ as estimated from the analysis of the fall-off period comprises two components: The mechanical component $\left(S_{m}\right)$, which is needed for formation damage estimation, and the biphase skin component $\left(\mathrm{S}^{*}\right)$ due to the presence of different saturation regions as a consequence of injection. The total skin is related to the mechanical and biphase skin by the following equation:

$\mathrm{S}_{\mathrm{t}}=\mathrm{S}_{\mathrm{m}}+\frac{\mathrm{S}^{*}}{\mathrm{M}}$

where, $\mathrm{M}$ is the mobility ratio between the displacing fluid and the displaced fluid.

If the formation permeability-thickness product $(\mathrm{kh})$ and the mechanical skin $\left(\mathrm{S}_{\mathrm{m}}\right)$ are known, then the transient well productivity can be assessed. It should be reminded that the mechanical skin (and not the total skin) has to be accounted for in the productivity calculation because the biphase skin affects injection only. In fact, during production, when only hydrocarbons are present in the reservoir and monophase flow occurs, the total skin coincides with the mechanical skin.
In reservoir engineering the advancement of the saturation front of an injected fluid (generally water) immiscible with the hydrocarbons in place can be calculated analytically by using the Buckley-Leveret solution obtained under a number of simplifying hypotheses such as steady state flow, incompressible fluids, concurrent flow and mono-dimensional flow geometry (Willhite, 1986). The Buckley-Leverett equation is typically applied to evaluate the efficiency of oil displacement by water injection at the reservoir scale. However, numerical models are needed to represent all the non linearities of the problem and to simulate the actual fluid distribution in the reservoir. In order to approach analytically the problem of fluid displacement in injection tests some authors proposed solutions based on the Buckley-Leverett equation: Bratvold and Horne (1990) derived a non isothermal solution, applicable in the case of homogeneous reservoir fully penetrated by the well, little fluids compressibility, negligible heat conduction and temperature dependency considered for viscosity only; starting from Bratvold and Horne (1990) results, Levitan (2002) developed an analytical solution for decoupling saturation and temperature from pressure response; Peres et al. (2004) derived an approximate analytical solution for oil-water bi-phase flow, limited entry vertical well or horizontal well. In all these analytical solutions the saturation profiles is decoupled from temperature and pressure changes. However, if the reservoir is gas-bearing, the reservoir phase properties are strongly pressure and temperature dependent, increasing the nonlinearity of the problem and the assumption that saturations can be decoupled from temperature and pressure is no more acceptable. Furthermore, capillary pressures, gravitational gradients, vertical heterogeneity and anisotropy might also strongly influence the variation of fluid distribution in time and space. Only a numerical model capable to describe two phase flow in heterogeneous, anisotropic reservoirs and simultaneously accounting for all relevant phenomena, including fluids and rock interactions, allows simulation of the displacement process in a representative manner. The issue is extremely relevant because a correct simulation of the pressure and pressure derivative trends when injection testing is necessary to separate the mechanical and bi-phase skin components and thus assess the actual well deliverability. A model capable to capture and reproduce all phenomena taking place during an injection test, including capillarity, gravitational and thermal effects and formation heterogeneity and anisotropy was developed by Verga et al. (2008). 
Field experiences: The first documented example of a successful injection test campaign has been presented in the study by Beretta et al. (2006).

A total of 6 conventional tests of short duration (DST tests) were available from three vertical appraisal wells draining 3 different pools of the studied field. The reservoir is a naturally fractured carbonate formation mineralized with sour oil. Pay zones are 40-100 m thick for each pool. Injection tests were also available for all wells and most of the pools. The injected fluid was mainly brine.

The workflow adopted to verify whether injection tests were suited for reservoir characterization was structured in the following steps:

- Compare and validate the fall-off pressure response with the dynamic behavior observed in the conventional build-up tests. This step was aimed at identifying a consistent radial flow regime in the uncontaminated oil zone

- Estimate the average $\mathrm{kh}$, thus the effective oil permeability and the total skin factor $\left(\mathrm{S}_{\mathrm{tot}}\right)$

- Analyze the skin factor components. The study provided an estimation of the bi-phase skin component $\left(\mathrm{S}^{*}\right)$ and of the mechanical component $\left(\mathrm{S}_{\mathrm{m}}\right)$

- Calculate the well productivity based on the equation for the transient PI, which is a function of both the formation kh and mechanical skin $\mathrm{S}_{\mathrm{m}}$ as well as of the oil PVT properties

Because of the large quantity of available data, it was possible to verify the effectiveness of injection tests with respect to the results of conventional well testing. The results were presented in terms of a table summarizing the Value Of Information (VOI) of the performed injection tests (Table 1).

The calculated Productivity Indexes (PI) proved to be in good agreement with those measured through the conventional production tests in four of the six examined cases.

Table 1: Value Of Information (VOI) from injection/fall-off testsconfidence degree in main well testing targets

\begin{tabular}{ll}
\hline Target & Degree of confidence \\
\hline Fm. Pressure & Good \\
kh (oil zone) & Good \\
Average permeability to oil & Good \\
Total skin & Good \\
Bi-phase skin, $S^{*}$ & Sufficient \\
Mechanical skin, $S_{\mathrm{m}}$ & Sufficient \\
Productivity, PI & Sufficient \\
\hline
\end{tabular}

Another successful application of injection testing in place of conventional well testing was conducted in a light oil reservoir in the North Sea. The injection fluid was a filtered brine. All the reservoir and well parameters needed to assess productivity were obtained and satisfactorily compared to the production data recorded during the clean-up phase of the well.

Eventually, another injection test was performed by injecting diesel in an oil bearing formation, located onshore North Africa. Also in this case, the test proved to be effective for reservoir and productivity characterization.

\section{RESULTS AND DISCUSSION}

A closed chamber test is conducted producing the reservoir fluids in the tubing string. Some authors report that this technique is a valid alternative to conventional well testing because it offers great security and safety, yet it provides a reservoir fluid sample and all the needed data to evaluate the well productivity. However, there is no assurance about the nature of the produced fluids, which might be drilling and completion fluids rather than reservoir fluids, thus about the quality of the sample and of the obtained information for formation evaluation. Therefore, even though in some cases the methodology can be very successful, in other cases the test outcome might be very disappointing.

One of the most interesting new unconventional well testing methodologies is injection testing. Injection tests eliminate emissions and, except for fluid sampling, can provide all the information needed to estimate the well productivity at a reasonably low cost and with a good degree of reliability. It is recommended that the test interpretation is performed with a numerical model capable to account for two phase flow, fluids and rock interactions, capillary forces, gravitational and thermal effects and recognized formation heterogeneity and anisotropy. Only in this case, it is possible to correctly estimate the well deliverability, which requires knowledge of the pay zone permeability and of the mechanical skin, or permeability damage around the wellbore, due to invasion of drilling and completion fluids. Field applications proved the efficiency of the methodology in oil reservoirs. Experience of injection testing in gas reservoirs will hopefully be shared with the technical community soon, as some innovative tests have already been conducted in Europe. In gas and gas condensate bearing formations it is suggested that gas (nitrogen) is injected to minimize the bi-phase skin effects masking the actual pressure response of the reservoir. 
The downhole production/reinjection testing method is a well test procedure that allows production from a selected reservoir and injection of the produced volume into another permeable layer. In principle, it could be very effective to test one or even two layers in one time, as it combines traditional well testing, but with no surface emissions, with injection testing. In practice, production/reinjection testing is very challenging and would require the development of adapted tools acquire good quality data and efficiently monitor the test, of pumps with enough power to maintain injectivity even in the case of formation clogging due to suspended fines and of tools for reliable sampling of the formation fluids. To the best of the authors' knowledge, no field experiences have ever been conducted wordwide so far.

A Wireline Formation Test consists in producing the reservoir fluid directly in the wellbore using a downhole pump so as to avoid hydrocarbon flow at the surface. The result is a sort of mini pressure test of the formation. The major limitation of WFT is generally agreed to be the scale of measurement, both in terms of producing pay and depth of investigation, which makes the test not suited for predicting the future performance of the well. The main advantages of this methodology are that, in most cases, the test can be performed in a matter of minutes because the production period is extremely short and that representative formation fluid samples can be collected. Because of this latter aspect, Wireline Formation Testing should be seen as a complementary methodology to injection testing, where fluid samples cannot be recovered.

\section{CONCLUSION}

The strongest reason not to perform a conventional well test, where hydrocarbons are produced to the surface and need to be flared in all exploration and appraisal assets, is mainly its environmental impact. The decision to test has to be made taking into account the overall cost of acquiring the information. This implies an understanding of what that information is and whether it can be acquired by other means.

Alternative methods in well testing have been structured in the last years. Advances in technology and interpretation tools have paved the way for conducting tests which account for environmental, safety and costreduction issues. The advantages and limitations of each of them should be clearly understood in the oil industry for green testing to become, by all means, a valuable opportunity to reliably characterize a reservoir and the wells that will drain it.
It is convincement of the authors that by combining injection testing and Wireline Formation Testing it is possible to achieve all the targets of a conventional well testing with no surface hydrocarbon production, thus also increasing safety during operations, reducing testing costs due to reduced rig requirements, especially during injection testing.

\section{ACKNOWLEDGMENT}

The researchers greatly acknowledge and Dario Viberti (Petroleum Engineering Group of DITAG Department, Politecnico di Torino) for providing an important and valuable contribution to this study.

\section{REFERENCES}

Abbaszadeh, M. and M. Kamal, 1987. Pressuretransient testing of water-injection wells. Proceeding of the SPE Annual Technical Conference and Exhibition, SPE 16744, Dallas, Texas, pp: 115-124. DOI: 10.2118/16744-PA

Alexander, L.G., 1976. Theory and practice of the closed-chamber Drillstem test method. Proceeding of the SPE-AIME 51st Annual Fall Technical Conference and Exhibition, Oct. 3-6, SPE 6024, New Orleans, Lousiana, pp: 1539-1544. DOI: 10.2118/6024-PA

Banerjee, R., L.G. Thompson and A.C. Reynold, 1998. Injection/falloff testing in heterogeneous reservoirs (revision). SPEREE, 1: 519-517. DOI: $0.2118 / 52670-\mathrm{PA}$

Beretta, E., A. Tiani, G. Lo Presti and F. Verga, 2006. Injection tests as a reliable alternative to conventional well testing: A Real Field Experience. Proceeding of the SPE Europec/EAGE Annual Conference and Exhibition, June 12-15, SPE 100283, Vienna, Austria, pp: 12-15. DOI: 10.2118/100283-MS

Beretta, E., A. Tiani, G. Lo Presti and F. Verga, 2007. Value of injection testing as an alternative of conventional well testing: Field experience in a sour-oil reservoir. SPEREE, 10: 112-121. DOI: 10.2118/100283-PA

Bradley, H.B., 1987. Petroleum Engineering Handbook. Society of Petroleum Engineers, Richardson, TX., USA., ISBN: 1555630103, pp: 2000.

Bratvold, R.B. and R.N. Horne, 1990. Analysis of pressure-falloff tests following cold-water injection. Proceeding of the Annual Technical Conference and Exhibition, Oct. 2-5, SPE 18111, Houston, Texas, pp: 293-302. DOI: 10.2118/18111-PA 
Bourdet, D., 2002. Well Test Analysis: The Use of Advanced Interpretation Models. Elsevier, Amsterdam, ISBN: 0-444-50968-2, pp: 426.

Coelho, A.C.D., C. De Carmargo, E.T. Kato and V.M.Q.F. Legrand, 2005. Utilizing mini-dst for formation evaluation. Proceeding of the SPE Latin American and Caribbean Petroleum Engineering Conference, June 20-23, SPE 94963, Rio de Janeiro, Brazil, pp: 13. DOI: 10.2118/94963-MS.

El-Khazindar, Y., M.R. Darwish and A. Tengirsek, 2002. Environmental friendly well testing. Proceeding of the SPE International Conference on Health, Safety and Environment in Oil and Gas Exploration and Production, Mar. 20-22, SPE 74106, Kuala Lumpur, Malaysia, pp: 6. DOI: 10.2118/74106-MS

Garland, E., 2002. Environmental regulatory framework in the North Sea: An update of the existing and foreseeable constraints. Proceeding of the SPE Annual Technical Conference and Exhibition, Sept. 29-Oct. 2, SPE 77390, San Antonio, Texas, pp: 8. DOI: 10.2118/77390-MS

Garland, E., 2005. Environmental regulatory framework in Europe: An update. Proceeding of the 2005 SPE/EPA/DOE Exploration and Production Environmental Conference, Mar. 7-9, SPE 93796, Galveston, Texas, pp: 10. DOI: 10.2118/93796-MS

Gan, R.G., Y. Nai-Shyong and, C.O. Bennett, 2002. Application of injection tests for reservoir appraisals: A conceptual study. Proceeding of the SPE Annual Technical Conference and Exhibition, Sept. 29- Oct.2, SPE 77454, San Antonio, Texas, pp: 12. DOI: 10.2118/77454-MS

Hollaender, F., J.G. Filas, C.O. Bennett and A.C. Gringarten, 2002. Use of downhole production/reinjection for zero-emission well testing: Challenges and rewards. Proceeding of the SPE Annual Technical Conference and Exhibition, Sept. 29-Oct. 2, SPE 77620, San Antonio, Texas, pp: 10. DOI: 10.2118/77620-MS

Levitan, M.M., 2002. Application of water injection/falloff tests for reservoir appraisal: New analytical solution method for two-phase variable rate problems. Proceeding of the SPE Annual Technical Conference and Exhibition, Sept. 29Oct. 2, SPE 77532-MS, San Antonio, Texas, pp: 11. DOI: $10.2118 / 77532-\mathrm{MS}$

Levitan, M.M., 2003. Application of water injection/falloff tests for reservoir appraisal: New analytical solution method for two-phase variable rate problems (revision 2003). SPE J., 8: 341-349. DOI: $10.2118 / 87332-\mathrm{PA}$
Perrin, D., M. Caron, G. Gaillot, 1999. Well Completion and Servicing: Oil and Gas Field Development Techniques. Technip, ISBN: 2-71080765-3, pp: 325.

Peres, A.M.M., A.A. Boughrara, S. Chen, A.A.V. Machado and A.C. Reynolds, 2004. Approximate analytical solutions for the pressure response at a water injection well. Proceeding of the SPE Annual Technical Conference and Exhibition, Sept. 26-29, SPE 90079, Houston, Texas, pp: 17. DOI: 10.2118/90079-MS

Simmons, J.F. and A.S. Grader, 1985. Application of closed-chamber theory to backsurge completion testing. Proceeding of the SPE Annual Technical Conference and Exhibition, Sept. 1985, SPE 14252, Las Vegas, Nevada, pp: 527-535. DOI: 10.2118/14252-PA

Soliman, M.Y., M. Azari, J. Ansah and C.S. Kabir, 2004. Design, interpretation and assessment of short-term pressure-transient tests. Proceeding of the SPE Annual Technical Conference and Exhibition, Sept. 26-29, SPE 90837, Houston, Texas, pp: 13. DOI: 10.2118/90837-MS

Soliman, M.Y., M. Azari, J. Ansah and C.S. Kabir, 2005. Review and application of short-term pressure transient testing of wells. Proceeding of the 14th SPE Middle East Oil and Gas Show and Conference, Mar. 4-5, SPE 93560, Bahrain, pp: 14. DOI: $10.2118 / 93560-\mathrm{MS}$

Sosa, A., R. Raghavan and, T.J. Limon, 1981. Effect of relative permeability and mobility ratio on pressure falloff behavior. JPT., 33: 1125-1135. DOI: 10.2118/9398-PA

Verga, F., D. Viberti and E. Salina Borello, 2008. A new 3-d numerical model to effectively simulate injection tests. Proceeding of the SPE Europec/EAGE Annual Conference and Exhibition, June 9-12, SPE 113832, Rome, Italy, pp: 9-12. DOI: 10.2118/113832-MS

Whittle, T.M., J. Lee and A.C. Gringarten, 2003. Will wireline formation tests replace well tests? Proceeding of the SPE Annual Technical Conference and Exhibition, Oct. 5-8, SPE 84086MS, Denver, Colorado, pp: 12. DOI: 10.2118/84086-MS

Willhite, P., 1986. Waterflooding. SPE Textbook Series, Vol. 3, ISBN: 1555630057, pp: 326.

Woie, R., T.M. Hegre, T. Gravema and P.E. Berger, 2000. Downhole production testing, a cost effective, safe and environmentally friendly well test method. Proceeding of the SPE International Conference on Health, Safety and Environment in Oil and Gas Exploration and Production, June 2628, SPE 61183, Stavanger, Norway, pp: 11. DOI: 10.2118/61183-MS 